\title{
Drugs of Abuse Induce Apoptotic Features in PC12 Cells
}

\author{
M. T. OLIVEIRA, ${ }^{a}$ A. C. REGO ${ }^{a}$ T. R. A. MACEDO,${ }^{b}$ AND C. R. OLIVEIRA ${ }^{a}$ \\ ${ }^{a}$ Institute of Biochemistry, Faculty of Medicine and Center for Neuroscience and Cell \\ Biology of Coimbra, ${ }^{b}$ Institute of Pharmacology and Experimental Therapeutics, \\ Faculty of Medicine, University of Coimbra, 3004-504 Coimbra, Portugal
}

\begin{abstract}
Drugs of abuse induce the release of dopamine in the central nervous system, particularly in the mesolimbic-mesocortical pathway. As dopamine may act as a neurotoxin, in this study, we analyzed the effects of the drugs of abuse, cocaine, heroin, and amphetamine, on the neurodegeneration of PC12 cells, a dopaminergic cell line, by evaluating the activity of caspase- 3 and mitochondrial cytochrome $\mathrm{c}$ release. All the drugs were shown to induce caspase-3 activation, similarly to staurosporine, a classical inducer of apoptotic cell death. Furthermore, like staurosporine, the drugs of abuse induced a decrease in mitochondrial cytochrome c content, suggesting the involvement of the mitochondrial apoptotic pathway.
\end{abstract}

KEYWORDS: amphetamine; apoptosis; cocaine; dopamine; heroin; mitochondria; PC12 cells

\section{INTRODUCTION}

The repeated abuse of drugs is sustained by the activation of the mesolimbic/ mesocortical circuit, in which dopamine is the main neurotransmitter. Dopamine bears potential neurotoxicity due to its oxidative metabolism, which produces reactive oxygen species, namely hydrogen peroxide. Drug abuse is also associated with changes in brain function and neurodegenerative processes, which, for some drugs, have been shown to be associated with the induction of apoptotic cell death. ${ }^{1-3}$ Therefore, the study of the mechanisms involved in the neurodegeneration induced by these drugs may be useful to prevent further neural demise.

Apoptosis is a programmed form of cell death, executed by a family of proteases named caspases. This form of cell suicide can be triggered by several external or internal stimuli. When cellular homeostasis is affected, the mitochondrial apoptotic pathway is activated, inducing the release of cytochrome c, frequently associated with a loss of mitochondrial membrane potential. Caspase-9, classically considered as an initiator caspase, is further activated in the presence of Apaf-1 and dATP, and is responsible for activating the effector caspase-3. This caspase activates nuclear DNAses, inducing DNA fragmentation.

Address for correspondence: Prof. Catarina Oliveira, M.D., Ph.D., Institute of Biochemistry, Faculty of Medicine, Center for Neuroscience and Cell Biology of Coimbra, University of Coimbra, 3004-504 Coimbra, Portugal. Voice: +351-239-820190; fax: +351-239-822776.

catarina@cnc.cj.uc.pt

Ann. N.Y. Acad. Sci. 1010: 667-670 (2003). (C) 2003 New York Academy of Sciences. doi: 10.1196/annals.1299.121 
In this study, using a dopaminergic cell line (PC12 cells), we analyzed the activation of a central executioner caspase - caspase-3 - and the content of cytochrome c within the mitochondria, in cells exposed to cocaine, heroin, or amphetamine, as compared to staurosporine, a classical inducer of apoptotic cell death.

\section{METHODS}

\section{Culture of Undifferentiated PC12 Cells}

PC12 cells (ATCC) were cultured in $75 \mathrm{~cm}^{2}$ flasks, in RPMI 1640 medium (Sigma) supplemented with 10\% (v/v) horse serum, $5 \%(\mathrm{v} / \mathrm{v})$ bovine serum, $50 \mathrm{U} /$ $\mathrm{mL}$ penicillin, and $50 \mathrm{mg} / \mathrm{mL}$ streptomycin. Cultures were maintained at $37^{\circ} \mathrm{C}$ in a humidified incubator containing $95 \%$ air and $5 \% \mathrm{CO}_{2}$. The cells were plated on poly-L-lysine-coated multiwells at a density of 160,000 cells $/ \mathrm{cm} .{ }^{2}$ The cells were further incubated for $5 \mathrm{~h}$ in RPMI medium, containing $4 \%$ bovine and horse serums (in the same proportion as for culturing the cells), simple or supplemented with staurosporine $(1 \mu \mathrm{M})$ or the drugs of abuse, cocaine $(300 \mu \mathrm{M})$, heroin $(30 \mu \mathrm{M})$, and amphetamine $(300 \mu \mathrm{M})$. These concentrations were chosen based on our previous studies, in which we investigated the toxic effects of the drugs of abuse. ${ }^{4}$ In the present work lower concentrations of the drugs were tested to avoid induction of necrotic cell death. The use of culture medium with $4 \%$ serum concentration was previously shown not to affect the viability PC12 cells. ${ }^{5}$

\section{Caspase-3 Activity Assay}

The cells were lysed in lysis buffer (in mM: $25 \mathrm{HEPES}, 2 \mathrm{MgCl}_{2}, 1$ EDTA, 1 EGTA, 2 DTT, 0.1 PMSF and 1:1000 of protease inhibitor cocktail [chymostatin, leupeptin, antipain, and pepstatin A] $1 \mathrm{mg} / \mathrm{mL}$ ). The resulting extracts were frozen and thawed three times and further centrifuged at $15,000 \mathrm{~g}$ for $10 \mathrm{~min}\left(4^{\circ} \mathrm{C}\right)$. The supernatant ( $25 \mu \mathrm{g}$ of protein) was tested for the activity of caspase- 3 by reaction with Ac-Asp-Glu-Val-Asp-pNA (Ac-DEVD-pNA, Calbiochem) for $2 \mathrm{~h}\left(37^{\circ} \mathrm{C}\right)$, and the absorbance was measured at $405 \mathrm{~nm}$.

\section{Western Blotting Analysis of Mitochondrial Cytochrome C Content}

The cells were homogenized in sucrose buffer (in mM: 250 sucrose, 20 HEPES, $10 \mathrm{KCl}, 1.5 \mathrm{MgCl}_{2}, 1 \mathrm{EDTA}, 1 \mathrm{DTT}, 0.1 \mathrm{PMSF}$, and 1:1000 of protease inhibitor cocktail), and the mitochondrial fraction (P2) was obtained by subcellular fractionation. ${ }^{6}$ Cytochrome c was detected by Western blotting (15\% SDS-PAGE), following the incubation with an antibody against the denatured form of cytochrome $\mathrm{c}$ (Pharmingen, 1:500). The secondary detection was made with an alkaline-phosphatase-bound antibody. The bands were revealed with ECF (Amersham) and quantified using a STORM 860 device and the software Image Quant 5.0.

\section{RESULTS AND DISCUSSION}

Caspase- 3 is a central executioner of the apoptotic program that is activated by several types of apoptotic stimuli. Exposure of PC12 cells to $1 \mu \mathrm{M}$ staurosporine in- 


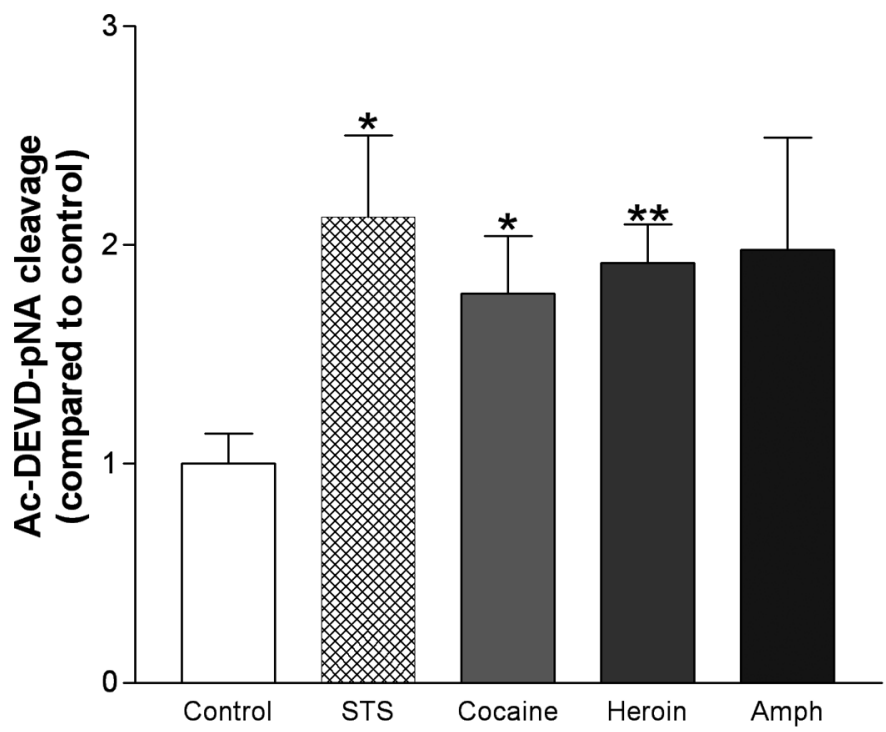

FIGURE 1. Caspase-3-like activity induced by the drugs of abuse. PC12 cells were incubated for $5 \mathrm{~h}$ with cocaine $(300 \mu \mathrm{M})$, amphetamine (Amph, $300 \mu \mathrm{M})$, or heroin $(30 \mu \mathrm{M})$, as compared to staurosporine (STS, $1 \mu \mathrm{M}$ ) in medium containing $4 \%$ serum. The extent of cleavage of Ac-DEVD-pNA was determined at $405 \mathrm{~nm}$, in control cells and in cells incubated with the drugs for $5 \mathrm{~h}$. The results are the means \pm SEM of at least 3 experiments performed in duplicate. Statistical analysis $(t$ test $){ }^{*} P<.05,{ }^{*} P<.01$, as compared to the control.

creased caspase-3 activity by about 2-fold (FIG. 1). Moreover, exposure to cocaine $(300 \mu \mathrm{M})$, heroin $(30 \mu \mathrm{M})$, or amphetamine $(300 \mu \mathrm{M})$ similarly increased the activity of this caspase (about 2-fold, FIG. 1). In order to determine if the mitochondrial apoptotic pathway was involved in caspase- 3 activation, we evaluated the content in mitochondrial cytochrome c (FIG. 2). When incubated with staurosporine, the mitochondrial cytochrome c content was decreased by about $30 \%$, in agreement with previous reports showing induction of cytochrome $\mathrm{c}$ release by staurosporine. ${ }^{6}$ PC12 cells incubated with the drugs of abuse also showed a decrease in the levels of mitochondrial cytochrome $\mathrm{c}$, when compared to control conditions. Heroin and amphetamine induced a decrease of about $40 \%$, whereas cocaine induced a $15 \%$ decrease in cytochrome c (FIG. 2). These differences, however, were not reflected by significant changes in caspase- 3 activation between the drugs tested (FIG. 1).

In previous studies, ${ }^{4}$ we have shown that heroin and amphetamine were more toxic to PC12 cells than cocaine and were able to induce intracellular dopamine depletion, associated with chromatin condensation, another feature of cell death. Our previous findings also suggest that heroin's effects may be mediated by oxidative stress, since PC12 cells incubated with this drug showed higher levels of intracellular peroxide production and increased dopamine metabolization, when compared to control cells. ${ }^{4}$ Furthermore, the effects of amphetamine may be due to the induction of metabolic dysfunction in these cells, since this drug was shown to decrease the 


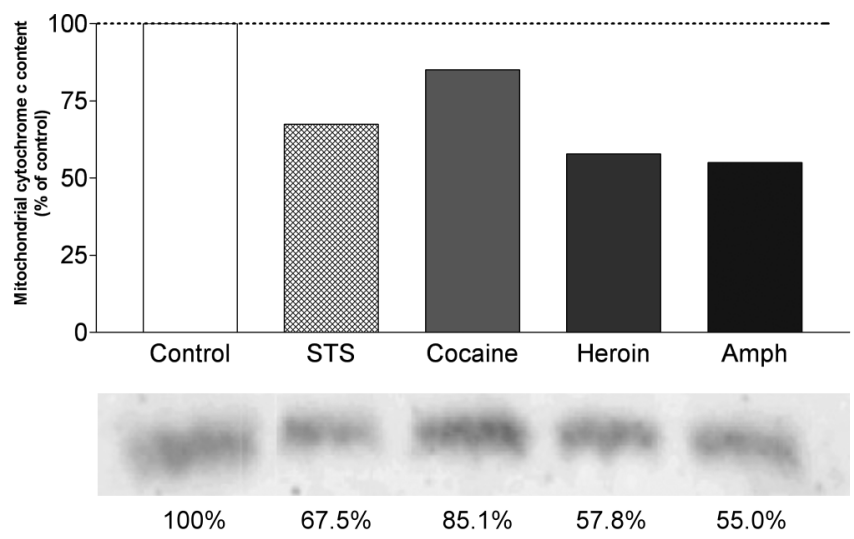

FIGURE 2. Mitochondrial cytochrome c levels upon exposure to the drugs of abuse. PC1 2 cells were incubated for $5 \mathrm{~h}$ with cocaine $(300 \mu \mathrm{M})$, amphetamine (Amph, $300 \mu \mathrm{M})$, or heroin $(30 \mu \mathrm{M})$, as compared to staurosporine (STS, $1 \mu \mathrm{M})$ in culture medium containing $4 \%$ serum, and the levels of cytochrome $\mathrm{c}$ in the mitochondrial fraction were determined by Western blot. The results show a representative experiment, expressed as a percentage of the levels of cytochrome $\mathrm{c}$ in the control.

ATP/ADP ratio, ${ }^{4}$ probably due to alkalinization of the mitochondrial matrix. ${ }^{1}$ The present results suggest that heroin and amphetamine activate the mitochondrial apoptotic pathway in PC12 cells. These results are in agreement with reports showing induction of apoptosis by amphetamine ${ }^{1}$ and heroin. ${ }^{3}$ Similar to our previous findings, ${ }^{4}$ cocaine seems to be the less toxic drug, because it decreased mitochondrial cytochrome c levels only by a certain extent, although it had significantly activated caspase-3. These results seem to be in agreement with previous studies showing that this drug of abuse induces apoptosis in several cell types (reviewed in Ref. 2).

\section{REFERENCES}

1. Davidson, C., A.J. Gow, T.H. LeE \& E.H. Ellinwood. 2001. Methamphetamine neurotoxicity: necrotic and apoptotic mechanisms and relevance to human abuse and treatment. Brain Res. Brain Res. Rev. 36: 1-22.

2. Zhang, L., Y. XiaO \& J. He. 1999. Cocaine and apoptosis in myocardial cells. Anat. Rec. 257: 208-216.

3. Fecho, K. \& D.T. Lysle. 2000. Heroin-induced alterations in leukocyte numbers and apoptosis in the rat spleen. Cell. Immunol. 202: 113-123.

4. Oliveira, M.T., A.C. Rego, M.T. Morgadinho, et al. 2002. Toxic effects of opioid and stimulant drugs on undifferentiated PC12 cells. Ann. N. Y. Acad. Sci. 965: 487496.

5. Oberdoerster, J., A.R. Kamer \& R.A. Rabin. 1998. Differential effect of ethanol on PC12 cell death. J. Pharmacol. Exp. Ther. 287: 359-365.

6. Rego, A.C., S. Vesce \& D.G. Nicholls. 2001. The mechanism of mitochondrial membrane potential retention following release of cytochrome $\mathrm{c}$ in apoptotic GT1-7 neural cells. Cell Death Differ. 8: 995-1003. 